\title{
Challenges Facing Physical Education Teachers in Jordan from Perspective of the Teachers Themselves
}

\author{
Mo'een Ahmad Oudat \\ Sport Rehabilitation Department, The Hashemite University, Zarqa, Jordan \\ Email: dr.moeenodat@gmail.com
}

Received 9 February 2016; accepted 25 April 2016; published 29 April 2016

Copyright (C) 2016 by author and Scientific Research Publishing Inc.

This work is licensed under the Creative Commons Attribution International License (CC BY). http://creativecommons.org/licenses/by/4.0/

(c) (i) Open Access

\begin{abstract}
This study aims at identifying the challenges facing Physical Education Teachers (PETs) in Jordanian public schools. The researcher utilized the descriptive method; and the study sample consisted of 150 male and female PETs who worked in public schools in Zarqa county during the $2013 / 2014$ academic year. The study sample was chosen by the intentional method. The researcher developed a special questionnaire about the challenges facing the PETs in Jordanian public schools. It consisted of five main domains (i.e., increased numbers of the students in the classroom; abilities, devices/instruments, and equipment; content of the academic curriculum; the school environment; and the school management). The validity of the instrument was verified by presenting it to arbitrators, whereas the reliability coefficient was calculated using Chronbach Alpha (0.89). The primary results showed a variance at the challenges level facing the PETs; as the most were related to the increased numbers of the students in the classroom. On the other hand, the least were those related to the school management. In addition, the results did not show statistically significant differences in the challenges degree facing the PETs according to the gender and years of experience variables. The researcher recommended providing the decision makers in the Jordanian Ministry of Education with an overview of the primary results to find the appropriate solutions for the challenges which the PETs faced.
\end{abstract}

\section{Keywords}

Challenges, Physical Education Teacher, Physical Education

\section{Introduction}

Workers in the educational field, in general, and physical education teachers (PETs) in particular, face many 
problems, which vary by the differences of the factors causing them. These factors are related to stress, putting them in front of wide responsibilities and challenges which need to face (Faedi et al, 2010). The school is one of the most important educational institutions that achieves integrated growth to the individuals from all physical, psychological, mental, social and health aspects; because of the different and various cognitive and skillful programs provided by the school, so that the individual will be able to adapt to his surrounding environment to achieve the objectives of the family and the community (BalSevich, 2005).

Additionally, the school is the first spring of all the scientific, physical, and cultural talents. It represents the first point from which the student starts to wider and larger prospects (Albert et al, 2006). It is an educational system that refines the individual's mental and intellectual powers, controls his/her emotional and psychological features, adjusts his/her childhood attitudes and trends, and orients his/her primary motivations with the acceptable principles and social values (Al-Shorman, 2009). The school is the first academy of the stars, which discovers the talents of the athletes since early ages. Through the school, every young person can practice his/her physical hobbies in healthy and sound atmospheres. Therefore, the sports activities become a fundamental component in forming the integrated personality of the individual, as well as in modifying the faulty behaviors to reach the highest levels, as it is the basic structure for the sports movement (Al-Sayeh, 2007).

Sports activities in the schools are considered as the spine in educating and cultivating the students through the various cultural and recreational activities. These sports activities encourage investing the leisure time, appreciating the responsibility, respecting self and others, and developing the ability to make the right decision. School sport is an educational and economical system that pumps cadres of the young people for the competitive sports and opening to the international markets (Oudat et al, 2009).

Physical education is one of the important aspects of the educational and teaching processes, especially in the current era, in which high values are set for the physical activity, as it has many positive effects on the individual. The PET is one of the basic pillars of the educational process, which its level and status in the community depends, to a wide extent, on the role and level of the teacher's performance and his/her achievement of the tasks and educational responsibilities that he had to accomplish (Husain et al, 1999).

In many countries, teaching the physical education is facing several challenges (Hardman, 2009), such as decreasing in the teaching time, curriculum, shortage in equipment, negative view of the teachers as well as students and guardians about physical education (Nyakweba, 2005).

PET is one of the prominent members at the school, who has influence on the development of the students' personalities, and supporting their high values. The role of PET lies in matching the students' trends and abilities with the school abilities to do the educational duties in sport framework. This could be achieved only by overcoming all the barriers and difficulties that prevent achievement of the aspired objectives he/she seeks to accomplish. PETs in Jordan face many challenges due to the challenges the school education itself is facing such as shortage of the resources and abilities, overcrowded classrooms, and shortage in the curricular, organizational and executive structure (Makhamreh, 2012).

In spite of the attention of the Jordanian Ministry of Education to the importance of the physical education in schools, through qualifying and training the teachers, and applying King Abdullah II Award for Physical Fitness, yet, the Jordanian schools are still suffering from many problems and difficulties (Al-Momani \& Khasawneh, 2007).

After the researcher reviewed the professional literature, he noticed a shortage in the studies that addressed the challenges facing the PETs in the Jordanian public schools from perspective of the teachers themselves. As far the knowledge of the researcher goes, this is the first study of its kind in Jordan, which comes to fill a gap in the literature related to these challenges, and to spot lights on some variables that may affect the challenges facing the PETs, such as gender and years of experience.

\subsection{Study Objectives}

The primary objectives of this study are to:

1) Identify the most challenges facing the physical education teachers in the Jordanian public schools.

2) Identify the differences in the challenges facing the physical education teachers in the Jordanian public schools attributed to gender variable.

3) Identify the differences in the challenges facing the physical education teachers in the Jordanian public schools attributed to years of experience variable. 


\subsection{Study Questions}

The primary study questions are:

1) What are the most challenges facing the physical education teachers in the Jordanian public schools?

2) Are there statistically significant differences at the significance level $\alpha \leq 0.05$ in the challenges facing the physical education teachers in the Jordanian public schools attributed to the gender variable?

3) Are there statistically significant differences at the significance level $\alpha \leq 0.05$ in the challenges facing the physical education teachers in the Jordanian public schools attributed to the years of experience variable?

\section{Methodology}

\subsection{Study Design}

The researcher used a descriptive design using survey methodology due to its relevance to the nature of this study.

\subsection{Study Population and Sample}

The study population consisted of all male and female PETs in the public schools located in Zarqa county in Jordan ( $N$ = 175) during the academic year 2013/2014. The study sample was chosen by the intentional manner, and the sample consisted of (150) participants (i.e., 86\% of the total study population); 78 male and 72 female teachers.

\subsection{Study Variables}

The dependent variable is the challenges facing the PETs in the Jordanian public schools, whereas the independent variables are gender (male, female) and years of experience in teaching (less than 5 years, 6 - 10 years, 11 15 years, and more than 16 years).

\subsection{Study Instrument}

A special questionnaire was developed to identify the challenges facing the PETs in the Jordanian public schools. The questionnaire included (25) items distributed over the following five domains: increased numbers of the students in the classroom; abilities, devices/instruments, and equipment; content of the academic curriculum, the school environment and the school management). The questionnaire was administered after obtaining the participants' consent in advance. The field-training students helped in the process of distributing and collecting the questionnaires. To determine the problem degree, the researcher used the Likert-type scale, which is one of the most famous types and most commonly used for developing the measurements and psychological tests. Several studies (e.g, Makhamreh, 2012; Shihadi, 2012; Ahmad, 2010), which addressed the challenges facing the teachers were reviewed in order to determine the following percentages of the problem degree:

$80 \%$ and more: Very high problems degree,

70\% - 79.9\%: High problems degree,

60\% - 69.9\%: Medium problems degree,

$50 \%$ - 59.9\%: Low problems degree,

49.9\% and less: Very low problems degree.

\subsection{Psychometric Properties}

The validity of the instrument was verified through presenting it to a panel of specialists in physical education teaching field. They were asked to review and provide feedback on the instrument concerning any need for changes in wording or additional items. The researcher modified the survey according to the specialists' comments. The reliability coefficient was calculated using Chronbach Alpha; the reliability coefficient value was (0.89).

\subsection{Statistical Analyses}

Data analyses were performed by using statistical Package for Social Sciences (SPSS). Descriptive statistics (i.e., 
means, standard deviations, and percentages) was computed to answer the first question; t-test was used to answer the second question; and One-way ANOVA was utilized to answer the third question.

\section{Results and Discussion}

\subsection{Results and Discussion Related to the First Question}

The results related to the first question "What are the most challenges facing the physical education teachers in the Jordanian public schools?” are presented in Tables 1-6.

Table 1. Means, standard deviations, and percentages scores of the participants responses $(n=150)$ to the items of the first domain which is the challenges related to the increased numbers of the students in the classroom, arranged by the problem degree.

\begin{tabular}{|c|c|c|c|c|}
\hline Items & $M^{*}$ & $\mathrm{SD}^{* *}$ & $\%$ & Problem Degree \\
\hline I cannot teach the skills very well & 4.83 & 1.62 & 96. 60 & Very High \\
\hline The instruments are insufficient for the students & 4.59 & 1.47 & 91.80 & Very High \\
\hline Depriving some students from the participation & 4.18 & 1.41 & 83.60 & Very High \\
\hline Disorder prevails during the lesson & 3.92 & 1.28 & 78.40 & High \\
\hline $\begin{array}{l}\text { It is difficult to divide and distribute the } \\
\text { Students }\end{array}$ & 3.50 & 1.23 & 70.00 & High \\
\hline Overall mean & 4.20 & 1.40 & 84.10 & Very High \\
\hline
\end{tabular}

*Means; **Standard Deviations.

Table 2. Means, standard deviations, and percentages scores of the participants responses $(n=150)$ to the items of the second domain which is related to the challenges of the abilities, devices/instruments, and equipment; arranged by the problem degree.

\begin{tabular}{|c|c|c|c|c|}
\hline Items & $\mathrm{M}^{*}$ & $\mathrm{SD}^{* *}$ & $\%$ & Problem Degree \\
\hline The instruments are not available for most of the sport games. & 4.67 & 1.60 & 93.40 & Very High \\
\hline Places to store the instruments in a right manner are not available & 4.58 & 1.51 & 91.60 & Very High \\
\hline The security and safety factors in the playgrounds are not available & 4.32 & 1.48 & 86.40 & Very High \\
\hline The instruments and equipment in the schools are insufficient & 3.78 & 1.19 & 75.60 & High \\
\hline Inability to maintain the instruments continuously. & 3.32 & 1.12 & 66.40 & Medium \\
\hline Overall mean & 4.13 & 1.38 & 82.70 & Very High \\
\hline
\end{tabular}

*Means; **Standard Deviations.

Table 3. Means, standard deviations, and percentages scores of the participants responses $(n=150)$ to the items of the third domain which is the challenges related to the content of the academic curriculum, arranged by the problem degree.

\begin{tabular}{|c|c|c|c|c|}
\hline Items & $\mathrm{M}^{*}$ & $\mathrm{SD}^{* *}$ & $\%$ & Problem Degree \\
\hline $\begin{array}{c}\text { The curriculum doesn't appropriate for the educational } \\
\text { environment }\end{array}$ & 4.72 & 1.57 & 94.40 & Very High \\
\hline $\begin{array}{c}\text { The curriculum doesn't keep up with the ongoing } \\
\text { development }\end{array}$ & 4.55 & 1.52 & 91.00 & Very High \\
\hline Curriculum objectives are unclear & 3.83 & 1.35 & 76.60 & High \\
\hline $\begin{array}{l}\text { Professionals do not participate in preparing the content } \\
\text { of the curriculum }\end{array}$ & 3.52 & 1.08 & 70.40 & High \\
\hline $\begin{array}{c}\text { The curriculum doesn't take into account the students' } \\
\text { needs }\end{array}$ & 2.98 & 1.50 & 59.60 & Low \\
\hline Overall mean & 3.92 & 1.41 & 78.40 & High \\
\hline
\end{tabular}

*Means; **Standard Deviations. 
Table 4. Means, standard deviations, and percentages scores of the participants responses $(n=150)$ to the items of the fourth domain which is the challenges related to the school environment, arranged by the problem degree.

\begin{tabular}{|c|c|c|c|c|}
\hline Items & $M^{*}$ & $\mathrm{SD}^{* *}$ & $\%$ & Problem Degree \\
\hline Increasing numbers of the students in one classroom. & 4.63 & 1.55 & 92.60 & Very High \\
\hline Practice time is short and unsuitable & 4.50 & 1.28 & 90.00 & Very High \\
\hline Playgrounds do not help playing in good manner & 3.42 & 1.18 & 68.40 & Medium \\
\hline $\begin{array}{c}\text { Very few incentives that encourage participation in } \\
\text { sports }\end{array}$ & 3.35 & 1.25 & 67.00 & Medium \\
\hline Students are unwilling to participate in the lesson. & 2.85 & 1.38 & 57.00 & Low \\
\hline Overall mean & 3.75 & 1.33 & 75.00 & High \\
\hline
\end{tabular}

*Means; **Standard Deviations.

Table 5. Means, standard deviations, and percentages scores of the participants responses $(n=150)$ to the items of the fifth domain which is the challenges related to the school management, arranged by the problem degree.

\begin{tabular}{|c|c|c|c|c|}
\hline Items & $\mathrm{M}^{*}$ & $\mathrm{SD}^{* *}$ & $\%$ & Problem Degree \\
\hline The school management looks negatively at the physical education & 4.75 & 1.60 & 95.00 & Very High \\
\hline The school management infringes the physical education lesson & 4.28 & 1.58 & 85.60 & Very High \\
\hline $\begin{array}{l}\text { Lack of financial support from the school management for the } \\
\text { activities and sport participation }\end{array}$ & 3.83 & 1.48 & 76.60 & High \\
\hline $\begin{array}{l}\text { Students are engaged in other things during the } \\
\text { physical education lesson }\end{array}$ & 3.12 & 1.45 & 62.40 & Medium \\
\hline $\begin{array}{l}\text { The school management infringes on the special } \\
\text { funds for the physical education }\end{array}$ & 2.57 & 1.07 & 51.40 & Low \\
\hline Overall mean & 3.71 & 1.44 & 74.20 & High \\
\hline
\end{tabular}

*Means; **Standard Deviations.

Table 6. Means, standard deviations, and percentages scores of the five domains of the study, arranged in a descending order by the problem degree.

\begin{tabular}{|c|c|c|c|c|}
\hline Study Domains & $M^{*}$ & $\mathrm{SD} * *$ & $\%$ & Problem Degree \\
\hline $\begin{array}{l}\text { Challenges related to the increased numbers of the } \\
\text { students in the classroom }\end{array}$ & 4.20 & 1.40 & 84.10 & Very High \\
\hline $\begin{array}{l}\text { Challenges related to the abilities, devices/instruments, } \\
\text { and equipment }\end{array}$ & 4.13 & 1.38 & 82.70 & Very High \\
\hline $\begin{array}{c}\text { Challenges related to the content of the academic cur- } \\
\text { riculum }\end{array}$ & 3.92 & 1.41 & 78.40 & High \\
\hline Challenges related to the school environment & 3.75 & 1.33 & 75.00 & High \\
\hline Challenges related to the school management & 3.71 & 1.44 & 74.20 & High \\
\hline Overall mean & 3.94 & 1.41 & 78.88 & High \\
\hline
\end{tabular}

*Means; **Standard Deviations.

Table 1 indicates that the highest challenge facing the PET related to the increased numbers of the students in the classroom is the challenge of teaching the skills in a good manner. On the other hand, the lowest challenge was the difficulty in dividing and distributing the students. The researcher ascribes this result to that the increased numbers of the students in the classroom weakens the ability of the teacher to teach the students, and to take into account the individual differences, as well as to provide students with the feedback to correct their errors. This result is consistent with the result of the study conducted by Harrison (2005), which indicated that many of the sports programs were difficult to apply due to the increased numbers of the students in the classroom, and to the insufficient learning time required for applying.

Table 2 shows that the highest challenge facing the PETS related to the abilities; devices/instruments; and equipment is the lack of the instruments for most of the sports games, whereas the lowest challenge was the ina- 
bility to maintain the instruments continuously. The researcher imputes this result to the lack of the funds/financial support for schools from the organizations in the community; to the high prices of the needed instruments; and to the decline of the budget given to the schools from Ministry of Education for the physical education. This interpretation is in an agreement with the results of the studies conducted by Orunaboka and Nwachukwu (2012) and Faedi et al (2010), which showed that the schools suffered from the following: lack of the financial abilities and availability of the playgrounds, insufficient of the sport equipment and instruments, decreasing of the budget given to the school sports, and poor maintenance of the equipment and instruments in the schools. In addition, the study of Mahmmoud (2003) indicated that many of the sport instruments and equipment are of a non-maintenance nature and are destroyed due to their low quality.

Table 3 reveals that the highest challenge facing the PETs related to the curriculum is that the curriculum does not appropriate for the educational environment, whereas the lowest challenge was that the curriculum does not take into account the students' needs. The researcher ascribes this result to that the curriculum contains certain academic units that cannot be applied in some Jordanian public schools due to the inexistence of a suitable educational environment to apply these units. This result is consistent with the study of Wanyama \& Quay (2014), which indicated that implementing the curriculum content requires special playgrounds. In addition, some high schools had eliminated the lessons of the physical education from their lesson schedule, since this subject is uncountable in the general average of the marks obtained.

Table 4 shows that the highest challenge facing the PETs related to the school environment is the increasing numbers of the students in one classroom, whereas the lowest challenge was that the students unwilling to participate in the lesson. The researcher ascribes this result to the unavailability of the sufficient and suitable yards for the numbers of the students. Additionally, the increased numbers of the students in one classroom negatively affects the student's participation in the physical education lesson, and makes the students feel that the practice time in the lesson is short. This result is consistent with the Wanyama's study (2011), which showed that many sport programs were difficult to apply due to inappropriateness of the school environment.

Table 5 shows that the highest challenge facing the PETs related to the school administration is that the view of the administration to the physical education is a negative one, whereas the lowest challenge was the infringing of the school management on the special funds for the physical education. The researcher attributes this result to that some PETs do not commit themselves in applying the physical education curriculum based on the teacher's guide which accredited by the Jordanian Ministry of Education, as well as the Media ignorance for the importance of the profession and its concentration only on the local and international championships. This result is consistent with a study conducted by Rainer et al (2012), which indicated that the school management has the main role in reducing the challenges facing the PETs at schools through providing the financial and moral support to the PETs.

Table 6 indicates that the responses of the study participants to the challenges were very high for both the first domain related to the increased numbers of the students in the classroom with (84.40\%), and the second domain related to the abilities, devices/instruments, and equipment with (82.60\%). In addition, the problem degree was high for the third domain related to the content of the academic curriculum; for the fourth related to the school environment; and for the fifth domain regarding the school management, with percentages of $(74.20 \%$, $75.00 \%$, and $78.40 \%$ ) respectively. The average mean of the participants responses on all the domains was (3.95) with a (78.92\%), which indicates the high level of the challenges facing the PETs in the Jordanian public schools. The researcher ascribes this result to the surrounding conditions around Jordan, and to the flow of large numbers of refugees into the country. This result is consistent with the results of Anmol (2015) that the increased numbers of the students in the classroom negatively affects the school sport in terms of the teaching style inside the classroom; applying the curriculum; distributing the lesson time; and providing the required equipment to the students to participate in most of the sport games.

\subsection{Results and Discussion Related to the Second Question}

The results of the second question, "Are there statistically significant differences at the significance level $\alpha \leq$ 0.05 in the challenges facing the physical education teachers in the Jordanian public schools attributed to the gender variable?” are presented in Table 7.

Table 7 indicates that there are not statistically significant differences at the significance level $\alpha \leq 0.05$ in the degree of the challenges facing the PETs in the five study domains, as well as the overall mean as related to 
Table7. T-Test results for the significance of the differences in the problems degree facing the physical education teachers in the study domains by gender.

\begin{tabular}{|c|c|c|c|c|c|}
\hline Domains & Gender & $\mathrm{M}^{*}$ & $\mathrm{SD}^{* *}$ & $\mathrm{~T}$ & $P$ Value \\
\hline \multirow{2}{*}{$\begin{array}{l}\text { Challenges related to the increased } \\
\text { numbers of the classroom students }\end{array}$} & Male & 4.06 & 1.30 & \multirow{2}{*}{12.89} & \multirow{2}{*}{0.82} \\
\hline & Female & 4.34 & 1.28 & & \\
\hline \multirow{2}{*}{$\begin{array}{l}\text { Challenges related to the abilities, } \\
\text { devices/instruments, and equipment }\end{array}$} & Male & 4.00 & 1.32 & \multirow{2}{*}{10.94} & \multirow{2}{*}{0.49} \\
\hline & Female & 4.26 & 1.43 & & \\
\hline \multirow{2}{*}{$\begin{array}{l}\text { Challenges related to the content of } \\
\text { the academic curriculum }\end{array}$} & Male & 3.75 & 1.45 & \multirow{2}{*}{10.16} & \multirow{2}{*}{0.57} \\
\hline & Female & 4.09 & 1.30 & & \\
\hline \multirow{2}{*}{$\begin{array}{l}\text { Challenges related to the school } \\
\text { environment }\end{array}$} & Male & 3.57 & 1.39 & \multirow{2}{*}{10.14} & \multirow{2}{*}{0.78} \\
\hline & Female & 3.93 & 1.21 & & \\
\hline \multirow{2}{*}{$\begin{array}{c}\text { Challenges related to the school } \\
\text { management }\end{array}$} & Male & 3.54 & 1.53 & \multirow{2}{*}{11.42} & \multirow{2}{*}{0.87} \\
\hline & Female & 3.88 & 1.41 & & \\
\hline \multirow{2}{*}{ Overall mean } & Male & 3.78 & 1.40 & \multirow{2}{*}{11.39} & \multirow{2}{*}{0.41} \\
\hline & Female & 4.11 & 1.33 & & \\
\hline
\end{tabular}

*Means; **Standard Deviations.

gender (male, female). The researcher attributes these results to the fact that both male and female schools in Zarqa country in Jordan are suffering from the same challenges (i.e., increased numbers of the classroom students, shortage of the instruments, and difficulty in implementing the curriculum). This result is consistent with the results of the studies conducted by Faedi et al. (2010); Ahmad (2010); and Oudat et al (2009), which revealed that the dealing of PETs with these challenges are close to each other due to the similar environmental and school conditions, as well as the shortage in the instruments and abilities.

\subsection{Results and Discussion Related to the third Question}

The results of the third question, "Are there statistically significant differences at the significance level $\alpha \leq 0.05$ in the challenges facing the physical education teachers in the Jordanian public schools attributed to the years of experience variable?” are presented in Table 8.

Table 8 indicates that there are not statistically significant differences at the significance level $\alpha \leq 0.05$ in the degree of the challenges facing the PETs in the five domains of the study, as well as the overall mean as related to the years of experience. The researcher ascribes the inexistence of such differences to the inability of the Jordanian Ministry of Education to implement the solutions related to these challenges, which exist since several years ago. The reason of that may be related to the current crisis that the education in the Jordanian schools suffers from due to the situations surrounding the whole Middle East area. These conditions have a negative effect on implementing the sport programs and activities, as the school sport became mere written programs and activities that are difficult to apply.

\section{Conclusion}

The results of this study show that there are differences in the challenges level facing the PETs. The largest challenge appeared in the first rank was the domain related to the increased numbers of the students in the classroom, especially in PETs' inability to teach the skills in a good manner. The domain related to the abilities, devices/instruments, and equipment came in the second rank, with emphasis on the lack of the instruments for most of the sport games. The third rank was the domain related to the academic curriculum content, with emphasis on the inappropriateness of the curriculum content for the educational environment. The challenge of the school environment was in the fourth rank, with emphasis on the overcrowded students in one classroom. Finally, the domain related to the school management ranked fifth and last, with emphasis on the negative view of the school management about the physical education. 
Table 8. One-way ANOVA results for the significance of the differences in the problems degree facing the physical education teachers in the study domains by years of experience.

\begin{tabular}{ccc|cc}
\hline & $\begin{array}{c}\text { Source of } \\
\text { Variance }\end{array}$ & $\begin{array}{c}\text { Sum of } \\
\text { Squares }\end{array}$ & $\begin{array}{c}\text { Degrees of } \\
\text { Freedom }\end{array}$ & $\begin{array}{c}\text { Mean Sum } \\
\text { of Squares }\end{array}$ \\
\hline $\begin{array}{c}\text { Overall Degree of the } \\
\text { Instrument }\end{array}$ & $\begin{array}{c}\text { Groups } \\
\text { Within Groups }\end{array}$ & 0.73 & 3 & 0.24 \\
& Total & 28.47 & 181 & 0.15 \\
\hline
\end{tabular}

\section{Recommendations}

The researcher recommends the necessity of briefing the decision makers in the Ministry of Education about the challenges facing the PETs in the Jordanian public schools, for the purpose of finding suitable solutions. Some of these solutions are to improve the ability of the teachers in teaching skills in a good manner; to provide instruments for most of the sport games; to modify the curriculum to make it appropriate for the educational environment; to reduce the number of students in a one classroom; and to change the negative view of the school management about the physical education.

\section{Limitations}

The study has several limitations. First, bias existed due to the way the researcher chose the study sample which was by the intentional method. Second, the results are generalizable only to the target population and to the same setting (i.e., physical education teachers at schools). Finally, the results of the study were based on perspective of the participants themselves.

\section{References}

Ahmad, N. (2010). Obstacles of Applied Instructional Media in Government Schools from the Perspective of Principals and Teachers. Journal of Research and Studies, 14, 4-6.

Albert, D., Terri, N., Wendy, K., Kevin, A., Elizabeth, H., \& Aleta, L. (2006). Peer School Problems in the Lives of Urban Adolescents: Frequency, Difficulty, and Relation to Adjustment. Journal of School Psychology, 44, 169-190. http://dx.doi.org/10.1016/j.jsp.2006.02.001

Al-Momani, Z., \& Khasawnih, A. (2007). The Difficulties Which Face School Sports in Irbid First Education Directorate from the Viewpoint of Physical Education Teachers. Abhath AL-Yarmouk Research: Series of Humanities and Social Sciences, 23, 1333-1351.

Al-Sayeh, M. (2007). Sport in Sociology in Physical Education. Alexandria: Dar Al-Wafa.

Al-Shorman, A. (2009). The Problems That Face Scholastic Sport at Educational Directorates in Zarqa Region. Dirasat: Educational Sciences, 36, 37-52.

Anmol (2015). Future Trends and Challenges in Physical Education and Sports Sciences. International Journal of Physical Education, Sports and Health, 1(3), 59-60.

BalSevich, V. (2005). Physical Education in the Schools: Ways to Modernize the Instruction. Russian Education and Society, 47, 82-91.

Faedi, F., Jalal, H., \& Erak, M. (2010). Occupational Stress of Physical Education Teacher. Journal of Physical Education Sciences, 2, 220-247.

Hardman, K. (2009). A Review of the Global Situation of Physical Education. International Journal of Physical Education, 46, 2-21.

Harrison, M. (2005). Public Problems, Private Solutions: School Choice and Its Consequences. Cato Journal, Cato Institute, 25, 197-215.

Husain, H., Nahar, H., Salem, M., AL Anabtawi, H., AL Qatan, T., Mokhtar, S., \& Jamal aldeen, A. (1999). Problems which Face Physical Education Teachers in Qatar, Journal of Education Faculty, 15, 265-315.

Mahmmoud, M. (2003). Needs of Physical Education Teacher of Service Training. Unpublished Master Thesis, Helwan University, Greater Cairo.

Makhamreh, K. (2012). The Main Obstacles of Teaching Physical Education in Schools and Educational Directorate Hebron from the Teachers’ Point. Journal of Al-Azhar University: Sseries of Humanities Sciences, 14, 103-128. 
Nyakweba, J. (2005). Status of PHYSICAL education in Butere Division Secondary Schools. Unpublished Master Thesis, Kenyatta University, Kahawa.

Orunaboka, T., \& Nwachukwu, E. (2012). Management of Physical Education Facilities, Equipment, and Supplies in secondary Schools in Nigeria: Issues and Challenges. Journal of Education and Practice, 3, 43-47.

Oudat, M., Bader, F., \& khasawneh, A. (2009). Analytical Studies for Challenges Which Face Physical Education Teacher in Jordanian public Primary School. Scientific Journal of Physical Education and Sport, 37, 21-36.

Rainer, P., Cropley, B., Jarvis, S., \& Griffiths, R. (2012). The Challenges of Providing High Quality Physical Education and School Sport Faced by Head Teachers within Primary Schools. Physical Education and Sport Pedagogy, 17, 429-446. http://dx.doi.org/10.1080/17408989.2011.603125

Shihadi, R. (2012). The Problems that Facing the Teachers in the Coeducation Basic Governmental Schools. Unpublished Master Thesis. Nablus: An-Najah National University.

Wanyama, M. (2011). The Challenges of Teaching Physical Education: Juxtaposing the Experiences of Physical Education Teachers in Kenya and Victoria (Australia). Unpublished Master Thesis. Parkville: University of Melbourne.

Wanyama, M., \& Quay, J. (2014). The Challenges of Teaching Physical Education: Juxtaposing the Experiences of Physical Education Teachers in Kenya and Victoria (Australia). African Journal for Physical, Health Education, Recreation and Dance, 20, 745-754. 